\title{
Lubrication Performance of $\alpha$-Zirconium Phosphates as an Anti-Wear Additive in Vegetable Oil-Based Anhydrous Calcium Grease
}

\author{
Yingjing Dai, Hong $\mathrm{Xu}$ * and Jinxiang Dong * \\ College of Chemistry and Chemical Engineering, Taiyuan University of Technology, Taiyuan 030024, China; \\ daiyingjing930329@163.com \\ * Correspondence: xuhongwork@126.com (H.X.); dongjinxiang@tyut.edu.cn (J.D.); \\ Tel.: +86-0351-6010-5508 (H.X. \& J.D.)
}

Received: 19 June 2018; Accepted: 16 July 2018; Published: 18 July 2018

\begin{abstract}
Vegetable oil has significant potential as a base oil, and substitute for mineral oil in grease formulation due to its biodegradability, low toxicity and excellent lubrication. This paper studied the development of vegetable oil-based greases with $\alpha-\mathrm{Zr}\left(\mathrm{HPO}_{4}\right)_{2} \cdot \mathrm{H}_{2} \mathrm{O}(\alpha-\mathrm{ZrP})$ as an additive, exploring base oil influence in tribological behavior. The results demonstrated that the addition of $\alpha-Z r P$ in vegetable-based greases is beneficial to anti-wear property. $\alpha$-ZrP particles exhibit good performance in anti-wear, friction-reduction and load-carrying capacity, and its tribological performances are better than the normally used molybdenum disulfide and graphite additives. Owing to its superior tribological properties as a vegetable oil-based grease additive, $\alpha$-ZrP holds great potential for use in environmentally friendly applications in the future.
\end{abstract}

Keywords: anti-wear additive; $\alpha-\mathrm{Zr}\left(\mathrm{HPO}_{4}\right) \cdot \mathrm{H}_{2} \mathrm{O}$; vegetable oil; anhydrous calcium grease

\section{Introduction}

The search, for environmentally friendly lubricants for use in industrial applications is considered a research priority in the fuel and energy sector. This is due to the rapid depletion of fossil fuel reserves, and environmental pollution from excessive mineral oil use and improper disposal of used lubricants [1]. Vegetable oil's high biodegradability, low toxicity, and good lubricating properties, makes it a potential alternative to fossil-based lubricants [2,3]. Their nontoxic and readily biodegradable characteristics pose less danger to the environment. Green lubricants are formulated from eco-friendly base oils and multifunctional additives [4-7]. Despite the inclusion of additives in small proportions, the development of green additives has gained special attention, thus these additives should possess special properties, but also be compatible with vegetable oils.

Development of vegetable oil-based greases is an active area of research. Greases may include various additives, for specific property enhancement [8,9]. Solid lubricants are a key ingredient, for most industrial grease formulations that protect equipment from wear and seizure under high contact loads, low speeds and high temperatures [10]. Classical solid lubricants used include two-dimensional layered materials, such as $\mathrm{MoS}_{2}$ and graphite, as their self-lubrication is primarily due to an interlayer shear mechanism. A recent study demonstrated that layered $\alpha$-ZrP may also function as a good lubricant additive. Compared to conventional layered materials, such as $\mathrm{MoS}_{2}$ and graphite, $\alpha-Z r P$ exhibited excellent tribological properties during laboratory testing [11-14]. This is attributed to the formation of a highly protective and slick tribofilm on sliding surfaces. Compared to $\mathrm{MoS}_{2}$ and graphite, $\alpha-\mathrm{ZrP}$ is also an inexpensive synthetic material, of which particle size and product quality can be controlled by adjusting synthesis conditions. Furthermore, $\alpha-\mathrm{ZrP}$ is a white powder and has been reported to be used as drug carriers [15,16]. 
This report highlights $\alpha$-ZrP as an environmentally friendly, anti-wear additive in vegetable oil-based greases. The friction and wear performances in different base oils were comparatively investigated using a ball-on-disk tribometer in reciprocating mode. Their sliding contact surfaces were analyzed after tests to ascertain the composition of tribofilms resulting from the $\alpha$-ZrP additive. In this work, two traditional additives, $\mathrm{MoS}_{2}$ and graphite, were used as references. White food-grade mineral oil was also used as a base oil to compare with vegetable oils.

\section{Experimental Section}

\subsection{Material}

Castor oil and coconut oil (chemically pure reagents) were purchased from Aladdin Industrial Corporation (Shanghai, China). White oil (food grade, viscosity of $90-110 \mathrm{~mm}^{2} / \mathrm{s}$ at $40{ }^{\circ} \mathrm{C}$ ) was purchased from Exxon Mobil Corporation (Irving, TX, USA). Calcium hydroxide $\left(\mathrm{Ca}(\mathrm{OH})_{2}, 95 \%\right)$ was obtained from Aladdin Industrial Corporation (Shanghai, China). TCI Industry Co., Ltd. (Shanghai, China) provided 12-hydroxystearic acid $\left(\mathrm{C}_{18} \mathrm{H}_{36} \mathrm{O}_{3}, 75 \%\right.$ ). Petroleum ether (boiling range of $90-120^{\circ} \mathrm{C}$ ) was procured from Tianjin Fengchuan Chemical Reagent Science and Technology Co. Ltd. (Tianjin, China) and distilled water was prepared in our laboratory. Details of $\alpha-\mathrm{ZrP}, \mathrm{MoS}_{2}$ and graphite are shown in Table 1.

Table 1. Details of selected $\alpha-\mathrm{ZrP}, \mathrm{MoS}_{2}$ and graphite powders.

\begin{tabular}{ccc}
\hline Materials & Size as Per Suppliers' Data & Supplier \\
\hline$\alpha-\mathrm{ZrP}$ & $\begin{array}{c}\text { particle size of } 0.5-0.6 \mu \mathrm{m} \text { and } \\
\text { thickness of } 50-100 \mathrm{~nm}\end{array}$ & $\begin{array}{c}\text { Synthesized in our laboratory } \\
\text { according to reported method [12] }\end{array}$ \\
\hline $\mathrm{MoS}_{2}$ & $\begin{array}{c}\text { particle size of } 1.5-3.5 \mu \mathrm{m} \text { and } \\
\text { thickness of } 50-100 \mathrm{~nm}\end{array}$ & $\begin{array}{c}\text { DAI ZO Corporation of Osaka } \\
\text { (Osaka, Japan) }\end{array}$ \\
\hline graphite & $\begin{array}{c}\text { particle size of } 1 \text { to } 7.0 \mu \mathrm{m} \text { and } \\
\text { thickness of } 100 \text { to } 200 \mathrm{~nm}\end{array}$ & $\begin{array}{c}\text { Aoyu Graphite Factory of Jixi } \\
\text { (Jixi, China) }\end{array}$ \\
\hline
\end{tabular}

\subsection{Tribological Test}

Anhydrous calcium-based grease was obtained according to Reference [14]. Base greases and additives with different concentrations were thoroughly mixed prior to the tests, and finely ground three times in a three-roller mill. The tribological performances of anhydrous calcium grease samples were evaluated on an Optimal SRV-V reciprocation friction tester by changing the base oils, additive concentrations, loads, frequencies and running times. The friction properties of conventional lubricants graphite and $\mathrm{MoS}_{2}$ were tested relative to $\alpha-Z r P$. Every test under fixed testing conditions was repeated thrice. The average mean friction coefficients of the three results were recorded. Details of the SRV high-frequency, linear-oscillating tester parameters are shown in Table 2.

Table 2. Parameters of SRV high-frequency, linear-oscillating tester.

\begin{tabular}{cc}
\hline & SRV High-Frequency, Linear-Oscillating Tester \\
\hline Maker & Optimal \\
\hline Contact of tribocouple and motion & Ball against disk reciprocating sliding motion \\
\hline Specimens & AISI 52100 steel ball $(\Phi 10 \mathrm{~mm}, 59-62 \mathrm{HRC})$, \\
& AISI 52100 steel disk ( $\Phi$ 24 mm, 59-62 HRC) \\
\hline Output & Friction coefficient \\
\hline \multirow{2}{*}{ Details of method } & stroke length $1 \mathrm{~mm}$, Frequency $30-60 \mathrm{~Hz}$, \\
& test duration $30-360$ min, at $80^{\circ} \mathrm{C}$ and load \\
& $300-1000 \mathrm{~N}$ \\
\hline
\end{tabular}




\subsection{Characterization and Analysis}

A three-dimensional (3D) optical profilometer (Zygo, ZeGage, Middlefield, CT, USA) was applied to observe the morphology of the worn surfaces and to measure the wear volume of the substrates. Worn surfaces were also investigated via scanning electron microscopy (HITACHI, TM-3000, Hitachi, Japan), and the elemental compositions of the worn surfaces were analyzed using an energy dispersive spectrometer (Bruker, QUANTAX 70, Billerica, MA, USA). The unit for wear rate is volumetric loss per unit load and distance slid by the disk $\left(\mathrm{mm}^{3} / \mathrm{N} \cdot \mathrm{m}\right)$ according to the following Equation (1).

$$
K_{\mathrm{V}}=\frac{W_{\mathrm{V}}}{F \times S}=\frac{W_{\mathrm{V}}}{F \times \text { frequency } \times \text { stroke } \times \text { time }}
$$

where $W_{\mathrm{V}}$ is wear volume, $F$ is the applied load, $S$ is the sliding distance of upper fixed ball relative to the lower rotating disk throughout the experiment. Frequency is the number of periodic changes completed per unit time, stroke is sliding $2 \mathrm{~mm}$ distance at each frequency and experimental time is duration of the test.

\section{Results}

\subsection{Effect of Additive Concentration}

The concentrations of the three additives were evaluated by varying them from 1.0 to $7.0 \mathrm{wt} \%$ under an applied load of 300 N. From Figure 1, compared with $\mathrm{MoS}_{2}$ and graphite, $\alpha-\mathrm{ZrP}$ improved the anti-wear properties of both vegetable oil grease and white oil grease, and had the lowest wear volume among the three additives. When the additive used was $\mathrm{MoS}_{2}$, the anti-wear property of the $\mathrm{MoS}_{2}$ castor oil grease was better than that of coconut oil grease. Graphite had little effect on the wear resistance of castor oil and coconut oil greases under the test concentrations. Both $\mathrm{MoS}_{2}$ and graphite improved the anti-wear property of the base grease when used as white oil grease additives, noting that $\mathrm{MoS}_{2}$ grease exhibited better performance than the graphite grease. Considering the importance of similar test conditions when conducting the friction test, the feasible concentration for the three additives was selected to be $3.0 \mathrm{wt} \%$ by the above analysis of the experimental results.
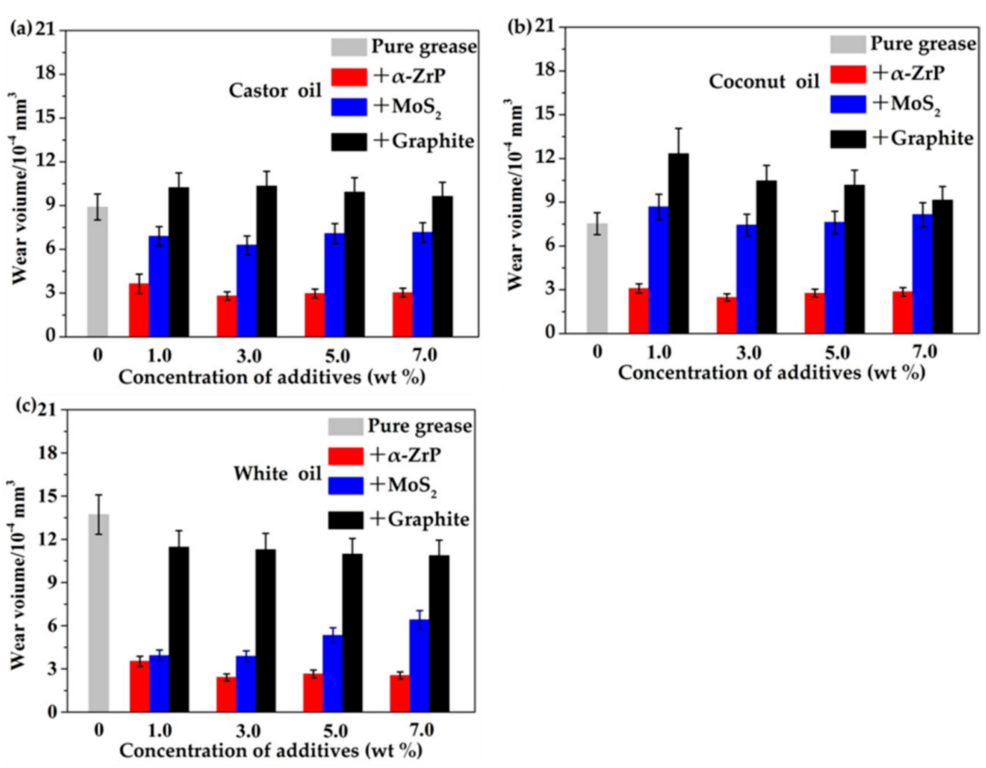

Figure 1. Wear volumes of the steel discs for $\alpha-\mathrm{ZrP}, \mathrm{MoS}_{2}$ and graphite under different concentrations in $(\mathbf{a}, \mathbf{b})$ vegetable oil and (c) white oil anhydrous calcium grease (load $300 \mathrm{~N}$, frequency $30 \mathrm{~Hz}$, temperature $80^{\circ} \mathrm{C}$, duration $30 \mathrm{~min}$ ). 


\subsection{Effect of Applied Load}

The tribological performances of the three, additive grease samples were then evaluated under applied loads ranging from 300 to 1000 N. Figure 2 illustrates the differences of the three additives under the same test conditions. As shown in Figure 2a,b, the carrying applied load for $\alpha-\mathrm{ZrP}$ vegetable oil grease increased to $1000 \mathrm{~N}$, whilst $\mathrm{MoS}_{2}$ and graphite grease reached $600 \mathrm{~N}$. The corresponding wear volume values $\left(\times 10^{-4} \mathrm{~mm}^{3}\right)$ for $\alpha$ - ZrP vegetable oil grease at $1000 \mathrm{~N}$ were $21.30 \pm 2.13$ (castor oil), $8.83 \pm 0.88$ (coconut oil), respectively. $\alpha$-ZrP vegetable oil grease had the lowest wear volume among the three additives. For $\mathrm{MoS}_{2}$ as a vegetable oil grease additive, the wear volume values were a little higher than those of graphite at $600 \mathrm{~N}$ (see Table 3). When the base oil was changed to white oil, the maximum operating loads for $\alpha-\mathrm{ZrP}, \mathrm{MoS}_{2}$ and graphite grease were 700, 600 and $600 \mathrm{~N}$ (see Figure 2c), respectively. The corresponding wear volume values were $\left(\times 10^{-4} \mathrm{~mm}^{3}\right)$ for $\alpha-\mathrm{ZrP}$, whilst $\mathrm{MoS}_{2}$ and graphite grease were $7.01 \pm 0.70,35.05 \pm 3.51$ and $34.08 \pm 3.41$, respectively, more details in Table 4 . $\alpha-\mathrm{ZrP}$ grease maintained the lowest wear volume among the three additives, and the wear values of $\mathrm{MoS}_{2}$ grease nearly equaled those of graphite grease. It was found that the anti-wear property of $\alpha-\mathrm{ZrP}$ changed marginally with the changes in applied loads and base oil. However, the wear volume values for $\mathrm{MoS}_{2}$ and graphite grease showed an upward trend as the load increased and their adaptations in vegetable oil did not perform as well as $\alpha-\mathrm{ZrP}$.
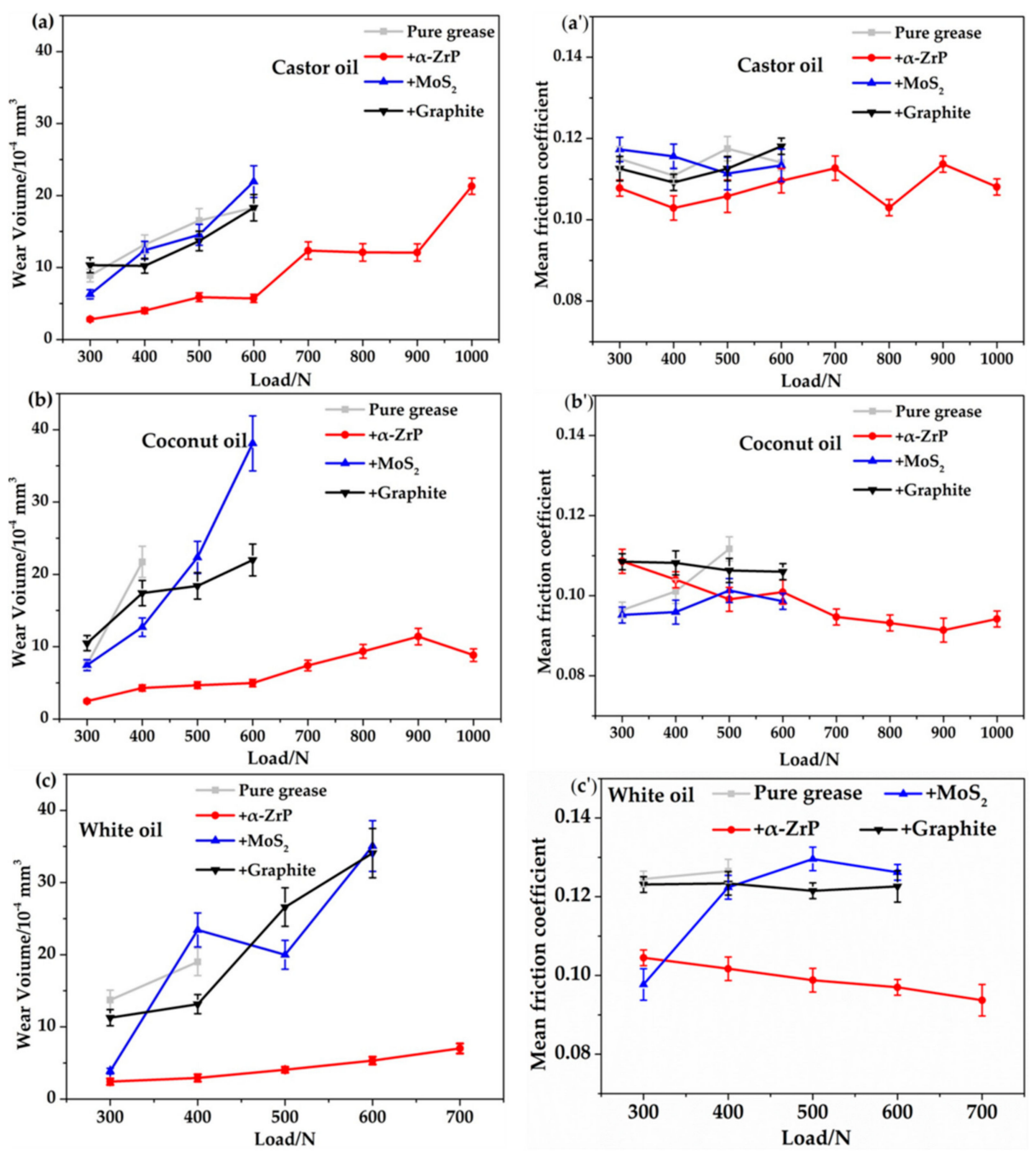

Figure 2. (a-c) Wear volumes and $\left(\mathbf{a}^{\prime}-\mathbf{c}^{\prime}\right)$ mean friction coefficients of vegetable oil and white oil grease samples under different applied loads (frequency $30 \mathrm{~Hz}$, temperature $80^{\circ} \mathrm{C}$, duration $30 \mathrm{~min}$ ). 
Table 3. Wear volumes and mean friction coefficients of vegetable oil and white oil grease samples at $600 \mathrm{~N}$.

\begin{tabular}{cccc}
\hline Oil & Additive & Wear Volume $\left(\times \mathbf{1 0}^{-\mathbf{4}} \mathbf{~ m m}^{\mathbf{3}}\right)$ & Mean Friction Coefficient \\
\hline \multirow{3}{*}{ Castor oil } & $\alpha-Z r P$ & $5.71 \pm 0.86$ & $0.110 \pm 0.015$ \\
& $\mathrm{MoS}_{2}$ & $21.94 \pm 2.19$ & $0.113 \pm 0.011$ \\
& graphite & $18.30 \pm 1.83$ & $0.118 \pm 0.012$ \\
\hline \multirow{3}{*}{ Coconut oil } & $\alpha-Z r P$ & $4.97 \pm 0.75$ & $0.101 \pm 0.015$ \\
& $\mathrm{MoS}_{2}$ & $38.11 \pm 3.81$ & $0.099 \pm 0.010$ \\
& graphite & $22.00 \pm 0.22$ & $0.106 \pm 0.011$ \\
\hline \multirow{3}{*}{ White oil } & $\alpha-Z r P$ & $5.32 \pm 0.80$ & $0.097 \pm 0.015$ \\
& MoS & $35.05 \pm 3.51$ & $0.126 \pm 0.013$ \\
& graphite & $34.08 \pm 3.41$ & $0.123 \pm 0.012$ \\
\hline
\end{tabular}

Table 4. Wear volumes of vegetable oil and white oil grease samples at maximum applied load.

\begin{tabular}{cccc}
\hline Oil & Additive & Maximum Load $\mathbf{( N )}$ & Wear Volume $\left(\times \mathbf{1 0}^{-\mathbf{4}} \mathbf{m m}^{\mathbf{3}}\right)$ \\
\hline \multirow{4}{*}{ Castor oil } & $\alpha-Z r P$ & 1000 & $21.30 \pm 2.13$ \\
& $\mathrm{MoS}_{2}$ & 600 & $21.94 \pm 2.19$ \\
& graphite & 600 & $18.30 \pm 1.83$ \\
\hline \multirow{3}{*}{ Coconut oil } & $\alpha-Z r P$ & 1000 & $8.83 \pm 0.88$ \\
& $\mathrm{MoS}_{2}$ & 600 & $38.11 \pm 3.81$ \\
& graphite & 600 & $22.00 \pm 0.22$ \\
\hline \multirow{3}{*}{ White oil } & $\alpha-Z r P$ & 700 & $7.01 \pm 0.70$ \\
& $\mathrm{MoS}_{2}$ & 600 & $35.05 \pm 3.51$ \\
& graphite & 600 & $34.08 \pm 3.41$ \\
\hline
\end{tabular}

The variation of the mean friction coefficient of the three additives grease was also shown in Figure $2 a^{\prime}-c^{\prime}$, where the friction behavior of the three additives grease exhibited analogous trends as the wear volume. When the base oil was castor oil, the friction coefficient of $\alpha-\operatorname{ZrP}$ grease was the smallest amongst the three additives grease samples under different applied loads. When the base oil was coconut oil, the friction coefficient of $\alpha$-ZrP grease showed instability between 300 and $600 \mathrm{~N}$. However above $600 \mathrm{~N}$, the mean friction coefficient was still the lowest among the three additives grease. When the base oil was white mineral oil, the behavior of $\alpha-\mathrm{ZrP}$ grease, for $300 \mathrm{~N}$ was better than graphite, and worse than $\mathrm{MoS}_{2}$. When the applied load increased, the friction coefficient of $\alpha-\mathrm{ZrP}$ grease was the smallest among the three additives grease.

\subsection{Effect of Reciprocating Frequency}

Figure 3 displayed the variation of wear volumes and mean friction coefficients, for the three additives grease samples under a series of frequencies ranging from 30 to $60 \mathrm{~Hz}$ under $300 \mathrm{~N}$. The wear value for $\alpha$-ZrP grease showed minimal change as the frequency increased from 30 to $60 \mathrm{~Hz}$. The corresponding wear volume values $\left(\times 10^{-4} \mathrm{~mm}^{3}\right)$ for $\alpha$-ZrP grease at $60 \mathrm{~Hz}$ were $2.92 \pm 0.44$ (castor oil), $3.17 \pm 0.48$ (coconut oil) and $3.05 \pm 0.46$ (white oil), respectively. $\alpha$-ZrP grease had the lowest wear volume value under vegetable oil grease and white oil grease. The wear values of $\mathrm{MoS}_{2}$ grease were lower than those of graphite grease under the same test conditions. In terms of friction reduction, the mean friction coefficients for the three additives grease samples showed minor variations (see Table 5). $\alpha$-ZrP grease did not exhibit any apparent advantages in friction-reducing performance under increasing frequency. 

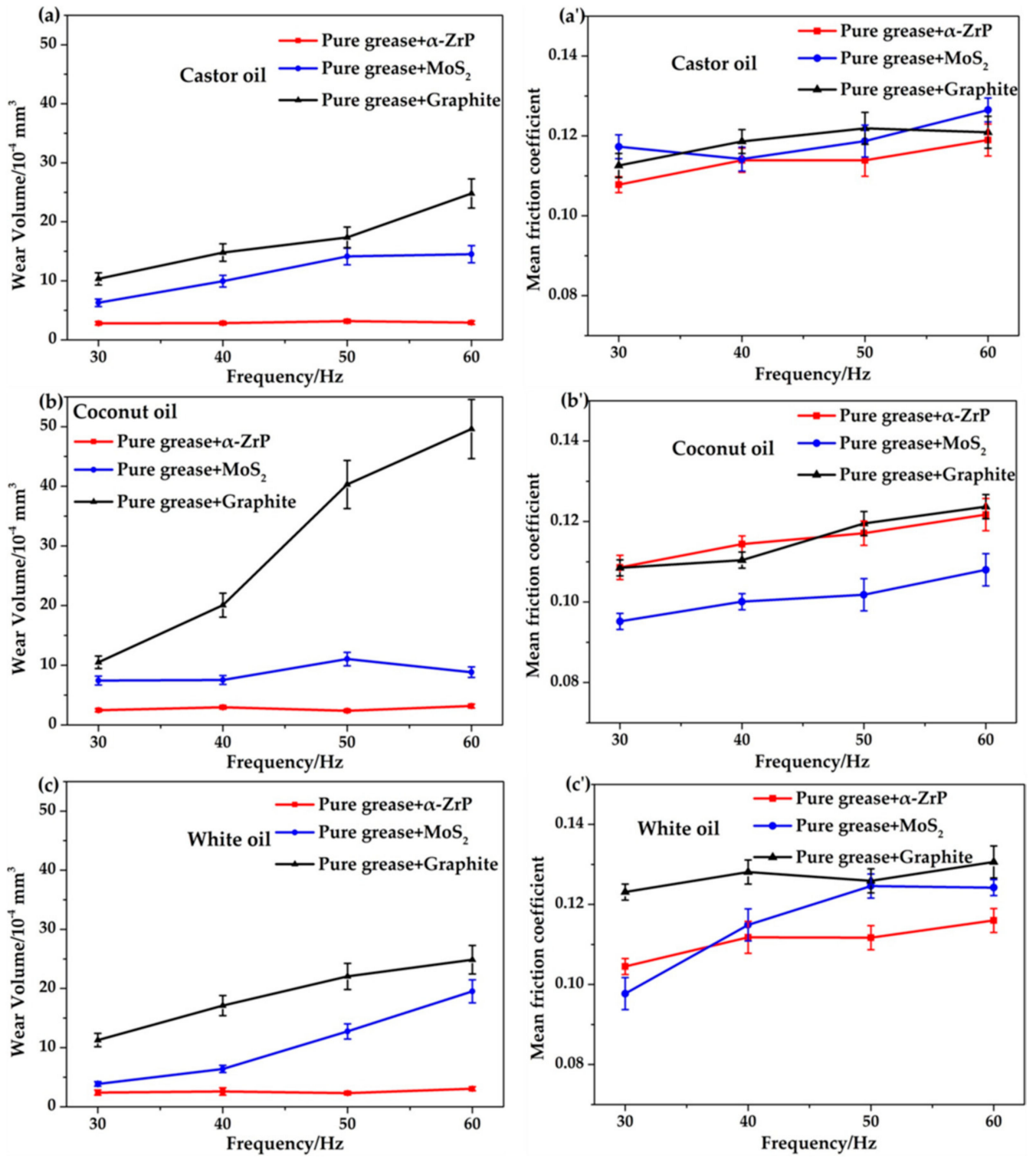

Figure 3. (a-c) Wear volumes and $\left(\mathbf{a}^{\prime}-\mathbf{c}^{\prime}\right)$ mean friction coefficients of vegetable oil and white oil grease samples under different applied frequencies (load $300 \mathrm{~N}$, temperature $80^{\circ} \mathrm{C}$, duration $30 \mathrm{~min}$ ).

Table 5. Wear volumes and mean friction coefficients of vegetable oil and white oil grease samples at $60 \mathrm{~Hz}$ under $300 \mathrm{~N}$.

\begin{tabular}{cccc}
\hline Oil & Additive & Wear Volume $\left(\times \mathbf{1 0}^{-\mathbf{4}} \mathbf{~ m m}^{\mathbf{3}}\right)$ & Mean Friction Coefficient \\
\hline \multirow{3}{*}{ Castor oil } & $\alpha-Z r P$ & $2.92 \pm 0.44$ & $0.119 \pm 0.018$ \\
& $\mathrm{MoS}_{2}$ & $14.52 \pm 1.45$ & $0.127 \pm 0.013$ \\
& graphite & $24.81 \pm 2.48$ & $0.121 \pm 0.012$ \\
\hline \multirow{3}{*}{ Coconut oil } & $\alpha-Z r P$ & $3.17 \pm 0.48$ & $0.122 \pm 0.018$ \\
& $\mathrm{MoS}_{2}$ & $8.84 \pm 0.88$ & $0.108 \pm 0.011$ \\
& graphite & $49.61 \pm 4.96$ & $0.124 \pm 0.012$ \\
\hline \multirow{3}{*}{ White oil } & $\alpha-Z r P$ & $3.05 \pm 0.46$ & $0.116 \pm 0.017$ \\
& MoS & $19.53 \pm 1.95$ & $0.124 \pm 0.013$ \\
& graphite & $24.86 \pm 2.49$ & $0.131 \pm 0.013$ \\
\hline
\end{tabular}




\subsection{Effect of Long Durations}

To further understand the tribological performance of $\alpha-\mathrm{ZrP}, \mathrm{MoS}_{2}$ and graphite as vegetable oil grease additives, the tribological test time was extended from 30 to $360 \mathrm{~min}$. As shown in Figure 4, $\alpha-\mathrm{ZrP}$ grease achieved the smallest wear rate among the three additives, and, as the friction time went on, its anti-wear advantages were more noticeable. As the friction time reached $360 \mathrm{~min}$, the wear rate values $\left(\times 10^{-9} \mathrm{~mm}^{3} /(\mathrm{N} \cdot \mathrm{m})\right)$ for $\alpha$-ZrP grease were $0.93 \pm 0.14$ (castor oil), $0.85 \pm 0.13$ (coconut oil) and $1.06 \pm 0.16$ (white oil), respectively. The corresponding wear rate values, for $\mathrm{MoS}_{2}$ grease were $18.27 \pm 1.83$ (castor oil), $14.51 \pm 1.45$ (coconut oil) and $4.11 \pm 0.41$ (white oil), respectively. The corresponding wear rate values for graphite grease were $52.77 \pm 5.28$ (castor oil), $74.32 \pm 7.43$ (coconut oil) and $5.67 \pm 0.57$ (white oil), respectively (see Table S1). From the results, $\alpha$-ZrP grease maintained the lowest wear rate under vegetable oil grease and white oil grease. The wear rate of $\mathrm{MoS}_{2}$ vegetable oil grease was clearly lower than that of graphite grease under the same test conditions. The anti-wear property of graphite vegetable oil grease was the most unfavorable. The corresponding mean friction coefficient of the three additives grease was also shown in Table S2. The mean friction coefficients, for the three additives grease samples showed little difference. As an additive, $\alpha$-ZrP had great adaptability in different types of base oils. In terms of adaptability $\mathrm{MoS}_{2}$ and graphite were inferior to $\alpha$-ZrP under vegetable oil-based grease. Amongst the three additives, graphite was most inferior. However, under white oil-based grease, there was no significant difference among the three additives in anti-wear properties.
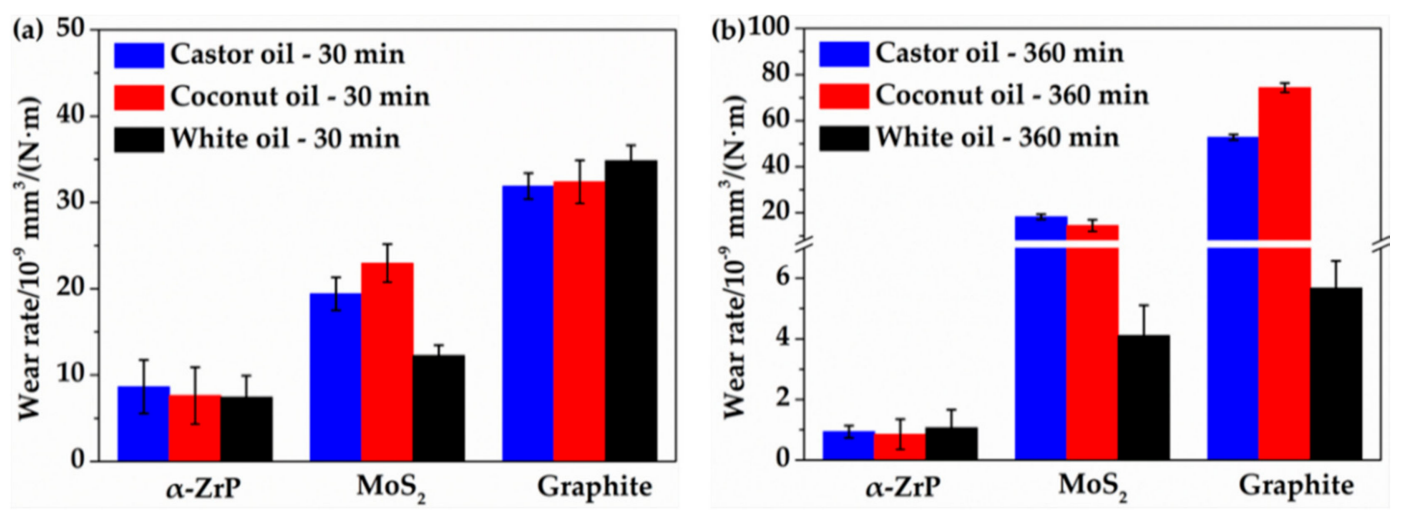

Figure 4. Wear rates of vegetable oil and white oil the grease samples at duration of (a) $30 \mathrm{~min}$ and (b) $360 \mathrm{~min}$ (load $300 \mathrm{~N}$, frequency $30 \mathrm{~Hz}$, temperature $80^{\circ} \mathrm{C}$ ).

Figure 5 depicts the variation of the dynamic coefficient of friction over time for the grease samples. The friction coefficient of $\alpha-\mathrm{ZrP}$ presented extremely stable curves under both vegetable oil grease and white oil grease. In comparison, the friction coefficients for $\mathrm{MoS}_{2}$ and graphite as vegetable oil grease additives showed sharp fluctuations. Moreover, when used as castor oil grease additives, the two friction coefficients fluctuated frequently. The unstable friction coefficients led to significantly increased disc wear rates, as shown in Figure 4. 

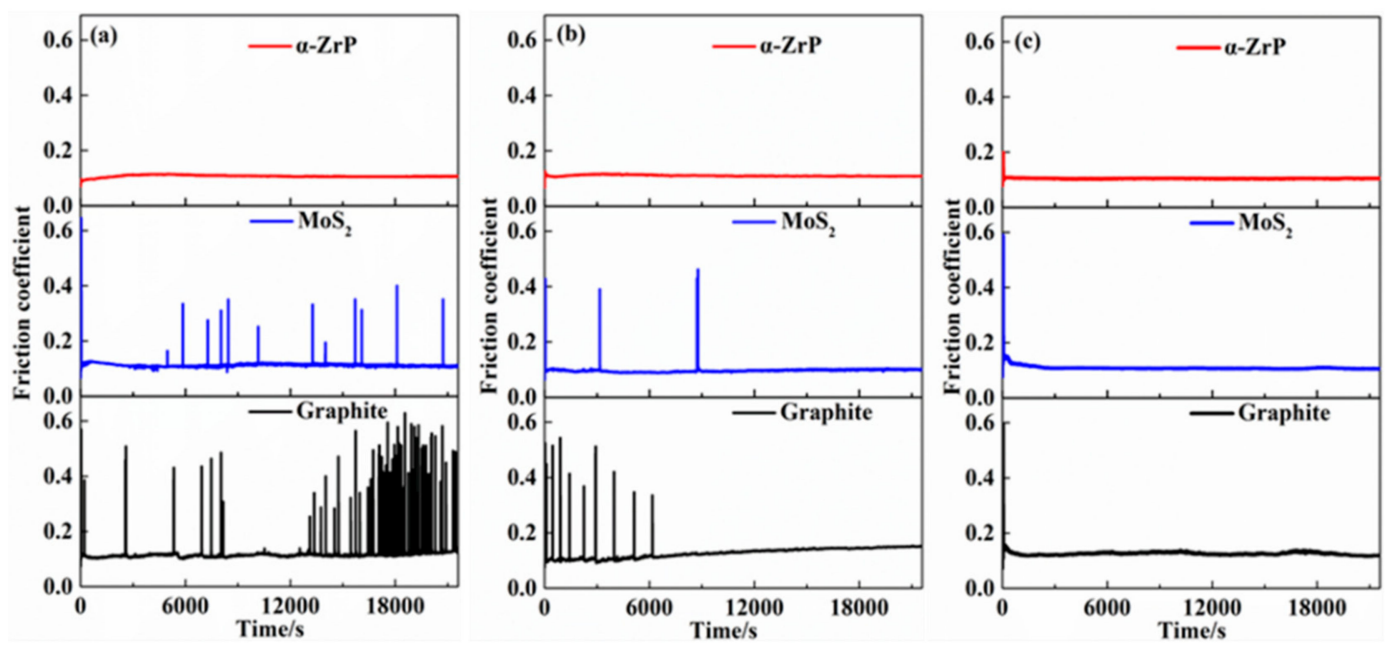

Figure 5. Dynamic friction coefficient of vegetable oil and white oil grease samples: (a) castor oil, (b) coconut oil and (c) white oil at $360 \mathrm{~min}$ test duration (load $300 \mathrm{~N}$, frequency $30 \mathrm{~Hz}$, temperature $80{ }^{\circ} \mathrm{C}$ ).

A 3D non-contact surface mapping profiler was employed to observe the topography characteristics of the worn surfaces, to better understand tribological behavior of the grease samples after long-duration experiments. Figure 6 exhibits the 3D profiles of the corresponding wear tracks on the discs after 360-min friction tests. It can be seen that the wear tracks of $\alpha$-ZrP grease were small and narrow. The wear tracks of $\mathrm{MoS}_{2}$ and graphite grease were relatively wider and deeper.

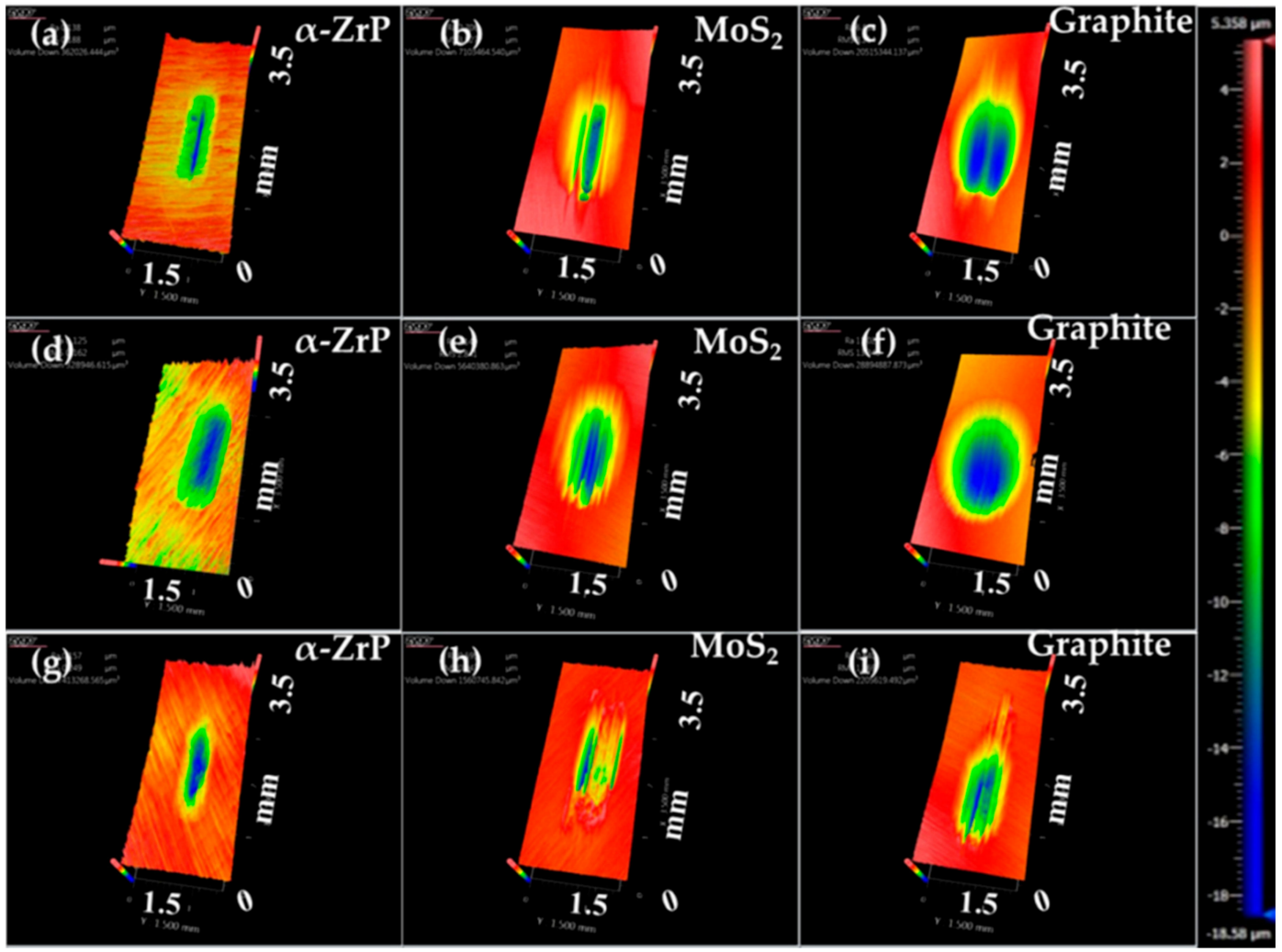

Figure 6. 3D microscopic images of disk wear scar: $(\mathbf{a}-\mathbf{c})$ castor oil grease, $(\mathbf{d}-\mathbf{f})$ coconut oil grease, and (g-i) white oil grease (load $300 \mathrm{~N}$, frequency $30 \mathrm{~Hz}$, temperature $80^{\circ} \mathrm{C}$, duration $360 \mathrm{~min}$ ). 
The 3D microscopic images of the corresponding wear scars on the steel balls are provided in Figure 7. For $\alpha-\mathrm{ZrP}$, small and smooth wear surfaces were observed at relatively low wear loss. On the wear surface lubricated by $\mathrm{MoS}_{2}$ and graphite grease, deep furrows along the motion direction were observed on the surface of the steel balls. The development of deep furrows may be attributed to the direct contact of the asperities at friction interface, where lubricants cannot provide a good protection film for the steel over a long test time. Considering both the steel disc wear volume and ball wear scar diameter, it was concluded that the anti-wear properties of $\alpha-\mathrm{ZrP}$ outperformed those of $\mathrm{MoS}_{2}$ and graphite, especially under a long test time.
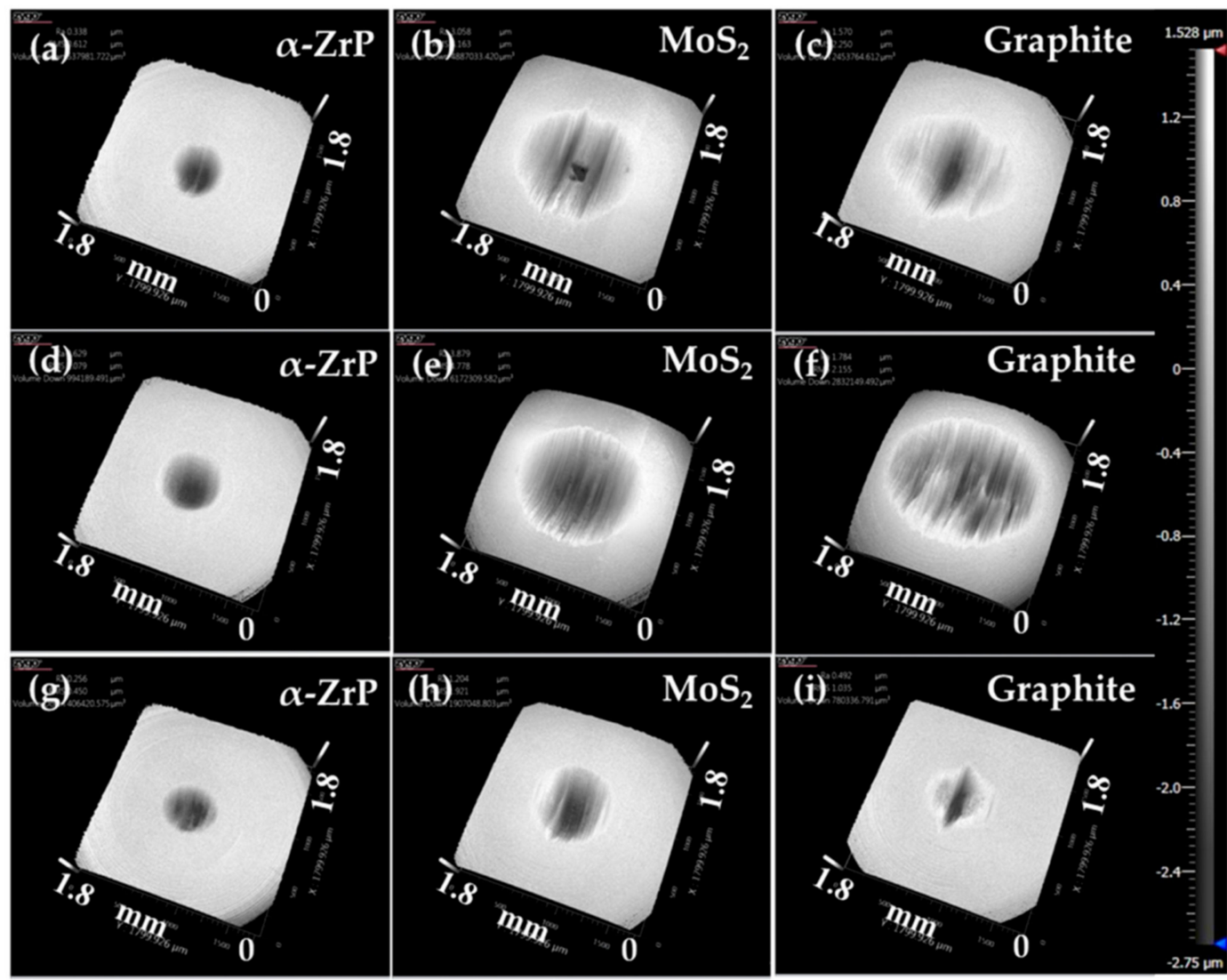

Figure 7. 3D microscopic images of ball wear scar: $(\mathbf{a}-\mathbf{c})$ castor oil grease, $(\mathbf{d}-\mathbf{f})$ coconut oil grease, and $(\mathrm{g}-\mathbf{i})$ white oil grease (load $300 \mathrm{~N}$, frequency $30 \mathrm{~Hz}$, temperature $80^{\circ} \mathrm{C}$, duration $360 \mathrm{~min}$ ).

SEM micrographs and EDS spectra of the lower discs are shown in Figure 8. The worn surface lubricated by $\alpha-Z r P$ grease was smoothest with no sharp furrows present on the wear track, displaying the best anti-wear properties. Meanwhile, the worn surfaces lubricated with $\mathrm{MoS}_{2}$ and graphite grease showed grooves and scuffing. Nevertheless, the furrows of $\mathrm{MoS}_{2}$ grease were shallower than those of graphite grease, revealing that $\mathrm{MoS}_{2}$ had better anti-wear properties than graphite, confirming the results of wear rates in Figure 4. From the area mapping EDS analysis for steel discs, the feature element $(\mathrm{Zr}, \mathrm{P})$ of $\alpha-\mathrm{ZrP}$ was presented on the wear surface. Additionally, Mo and S elements were also found on the disc surface lubricated by $\mathrm{MoS}_{2}$ grease. The presence of the feature elements confirmed that $\alpha-\mathrm{ZrP}$ and $\mathrm{MoS}_{2}$ can maintain the lubricant film on the wear surface for a longer time. The efficient protected film on the metal surface led to reduce wear. However, no additional $\mathrm{C}$ increment was found on the wear surface lubricated by graphite grease. Higher wear rates of graphite grease may be due to premature adhesion failure, which resulted in a nonprotective condition between the two sliding pairs. 

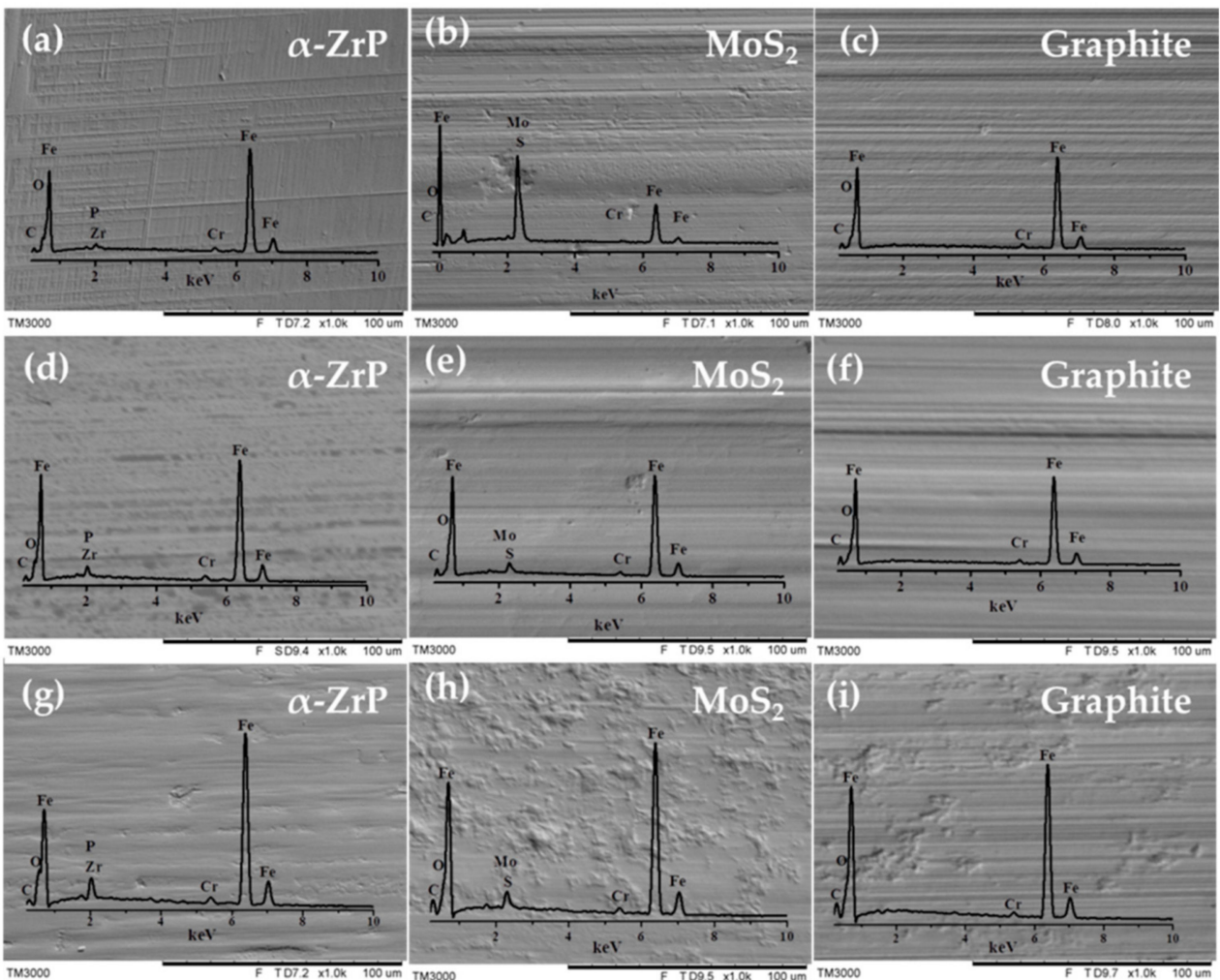

Figure 8. Scanning electron microscopy (SEM) images and Corresponding Energy Dispersive X-ray Spectroscopy (EDS) spectra of disk wear scar: (a-c) castor oil grease, $(\mathbf{d}-\mathbf{f})$ coconut oil grease, and $(\mathbf{g}-\mathbf{i})$ white oil grease (load $300 \mathrm{~N}$, frequency $30 \mathrm{~Hz}$, temperature $80^{\circ} \mathrm{C}$, duration $360 \mathrm{~min}$ ).

\section{Conclusions}

As a vegetable oil grease additive, $\alpha-\mathrm{ZrP}$ showed the best and most stable tribological performance, because of its more favorable crystal structure, the formation of a more protective tribofilm during the sliding process, and good adaptation in vegetable oils. This work confirmed the superior tribological behaviors of $\alpha-\mathrm{ZrP}$ as potential antifriction and anti-wear additives in vegetable oil-based lubricants and, thus, may help in practical applications by industry. More details about $\alpha-\mathrm{ZrP}$ as an Anti-Wear Additive are as below.

1. When the base oil is vegetable oil, the grease containing $\alpha$-ZrP showed good performance in anti-wear and friction-reduction, as well as load-carrying capacity, regardless of the testing applied load and frequency.

2. As the test time was extended from 30 to $360 \mathrm{~min}, \alpha-\mathrm{ZrP}$ grease could run steadily throughout the test, and had better anti-wear properties than those of graphite and $\mathrm{MoS}_{2}$ greases under the same test conditions.

3. Compared with $\mathrm{MoS}_{2}$ and graphite, $\alpha$-ZrP had better adaptability in vegetable oils.

Supplementary Materials: The following are available online at http:/ / www.mdpi.com/2075-4442/6/3/63/s1. Table S1. Wear rate $\left(\times 10^{-9} \mathrm{~mm}^{3} /(\mathrm{N} \cdot \mathrm{m})\right)$ of vegetable oil and white oil grease samples at duration of 30 and $360 \mathrm{~min}$. Table S2. Mean friction coefficients of vegetable oil and white oil grease samples at duration of 30 and $360 \mathrm{~min}$.

Author Contributions: J.D., H.X. and Y.D. conceived and designed the experiments; Y.D. performed the experiments and analyzed the data; Y.D. and H.X. wrote the paper.

Funding: This work was supported by the Key Program of National Natural Science Foundation of China (grant No. 21436008), the General Program of National Natural Science Foundation of China (grant No. 51372162), 
the Natural Science Foundation for Young Scientists of Shanxi Province, China (Grant No. 2015021032) and Ten Thousand Talents Program: Millions of Leading Engineering Talents.

Conflicts of Interest: The authors declare no conflicts of interest.

\section{References}

1. Betton, C.I. Lubricants and Their Environmental Impact. In Chemistry and Technology of Lubricants; Mortier, R.M., Fox, M.F., Orszulik, S.T., Eds.; Springer: Dordrecht, The Netherlands, 2010.

2. Fuks, I.G.; Evdokimov, A.Y.; Dzhamalov, A.A.; Luksa, A. Vegetable oils and animal fats as raw materials for the manufacture of commercial lubricants. Chem. Technol. Fuels Oils 1992, 28, 230-237. [CrossRef]

3. Hashem, A.I.; Abou Elmagd, W.S.I.; Salem, A.E.; El-Kasaby, M.; El-Nahas, A.M. Conversion of some vegetable oils into synthetic lubricants. Energy Sources Part A 2013, 35, 397-400. [CrossRef]

4. Garcés, R.; Force, M.E.; Salas, J.J. Vegetable oil basestocks for lubricants. Grasas Y Aceites 2011, 62. [CrossRef]

5. El-Adly, R.A.; Ahmed, H.B.; Modather, F.H. Jojoba and castor oils as fluids for the preparation of bio greases: A comparative study. Int. J. Sci. Eng. Res. 2014, 5, 755-762.

6. Mannekote, J.K. Synthesis and characterization of coconut oil based non soap greases. In Proceedings of the International Conference on Industrail Tribology, Pune, India, 7-9 December 2012.

7. Chtourou, M.; Trabelsi, M.; Frikha, M.H. Utilization of olive-residue oil in the formulation of lubricating calcium greases. J. Am. Oil Chem. Soc. 2004, 81, 809-812. [CrossRef]

8. Boner, C.J. Manufacture and Application of Lubricating Greases; Reinhold: New York, NY, USA, 1954.

9. Allison, J.R.; Blalock, W.L. Lubricating Grease. U.S. Patent 2,628,195, 10 February 1953.

10. Bowden, F.P.; Tabor, D. The Friction and Lubrication of Solids; Oxford University Press: Oxford, UK, 2001; Volume 1.

11. Liu, L.; Chen, Z.F.; Wei, H.B. Ionothermal synthesis of layered zirconium phosphates and their tribological properties in mineral oil. Inorg. Chem. 2010, 49, 8270-8275. [CrossRef] [PubMed]

12. Zhang, X.; Xu, H.; Zuo, Z.; Lin, Z.; Ferdov, S.; Dong, J. Hydrothermal synthesis of copper zirconium phosphate hydrate $\left[\mathrm{Cu}(\mathrm{OH})_{2} \mathrm{Zr}\left(\mathrm{HPO}_{4}\right)_{2} \cdot 2 \mathrm{H}_{2} \mathrm{O}\right]$ and an investigation of its lubrication properties in grease. ACS Appl. Mater. Interfaces 2013, 5, 7989-7994. [CrossRef] [PubMed]

13. Chen, L.; Zhang, X.; Xu, H.; Dong, J. Tribological investigation of two different layered zirconium phosphates as grease additives under reciprocating sliding test. Tribol. Lett. 2016, 64. [CrossRef]

14. Dai, Y.; Niu, W.; Zhang, X.; Xu, H.; Dong, J. Tribological investigation of layered zirconium phosphate in anhydrous calcium grease. Lubricants 2017, 5, 22. [CrossRef]

15. Saxena, V.; Diaz, A.; Clearfield, A.; Batteas, J.D.; Hussain, M.D. Zirconium phosphate nanoplatelets: A biocompatible nanomaterial for drug delivery to cancer. Nanoscale 2013, 5, 2328-2336. [CrossRef] [PubMed]

16. Sekhon, B.S.; Kamboj, S.R. Inorganic nanomedicine-Part 2. Nanomed. Nanotechnol. Biol. Med. 2010, 6, 612-618. [CrossRef] [PubMed]

(C) 2018 by the authors. Licensee MDPI, Basel, Switzerland. This article is an open access article distributed under the terms and conditions of the Creative Commons Attribution (CC BY) license (http://creativecommons.org/licenses/by/4.0/). 